REVIEW

\title{
Time to reconsider nonsurgical therapy of benign non-toxic multinodular goitre: focus on recombinant human TSH augmented radioiodine therapy
}

\author{
Søren Fast, Viveque Egsgaard Nielsen, Steen Joop Bonnema and Laszlo Hegedüs \\ Department of Endocrinology and Metabolism, Odense University Hospital, DK-500O Odense C, Denmark \\ (Correspondence should be addressed to S Fast; Email: soeren.fast@ouh.regionsyddanmark.dk)
}

\begin{abstract}
The treatment of benign multinodular goitre (MNG) is controversial, but surgery is recommended in large compressive goitres. While some patients decline surgery others may have contraindications due to comorbidity, since MNG is prevalent in the elderly. Therefore, non-surgical treatment alternatives are needed. Until recently, levothyroxine therapy was the preferred non-surgical alternative, but due to low efficacy and potential side-effects, it is not recommended for routine use in recent international guidelines. Conventional radioiodine $\left({ }^{131} \mathrm{I}\right)$ therapy has been used for two decades as an effective and safe alternative to surgery in the treatment of symptomatic non-toxic MNG. Since much higher activities of ${ }^{131}$ I are employed when treating non-toxic rather than toxic MNG, there has been reluctance in many countries to use this treatment modality. Frequently, the ${ }^{131} \mathrm{I}$-uptake in a non-toxic MNG is low, which makes ${ }^{131}$ I therapy less feasible. Another challenge is the negative correlation between the initial goitre size and goitre volume reduction (GVR). With its ability to more than double the thyroid ${ }^{131}$ I-uptake, recombinant human TSH (rhTSH) increases the absorbed radiation dose and thus enhances the GVR by $35-56 \%$ at the expense of up to fivefold higher rate of permanent hypothyroidism. An alternative strategy is to reduce the administered ${ }^{131}$ I-activity with a factor corresponding to the rhTSH induced increase in ${ }^{131}$ I-uptake. Hereby, the extrathyroidal irradiation can be reduced without compromising efficacy. Thus, although in its infancy, and still experimental, rhTSH-augmented ${ }^{131}$ I therapy may profoundly alter the non-surgical treatment of benign non-toxic MNG.
\end{abstract}

European Journal of Endocrinology 160 517-528

\section{Introduction}

Despite iodization programmes, simple goitre-defined as a euthyroid goitre that is not associated with thyroid autoimmunity or malignancy - still constitutes a major diagnostic and therapeutic challenge. Such goitres can be diffuse, uni- or multinodular (1). When applying ultrasound (US), most goitres have a nodular structure, particularly in the elderly (1). According to current thinking, they are caused by an interaction between genetic susceptibility and environmental triggers, iodine deficiency being the most important. There is no ideal treatment for benign multinodular goitre (MNG), as reflected by the lack of consensus in questionnaire surveys (2-5). Surgery is recommended when facing a large goitre or when malignancy cannot be ruled out $(6,7)$. However, it is important to recognise that a considerable proportion of patients refuse surgery, even in the context of a large symptomatic goitre, which underlines the need for non-surgical alternatives. The non-surgical treatment options are: iodine supplementation, levothyroxine $\left(\mathrm{LT}_{4}\right)$ therapy and radioiodine $\left({ }^{131} \mathrm{I}\right)$ therapy. In theory, percutaneous interventional therapy (laser photocoagulation or ethanol injection) is also an option in MNG, but so far it is only experimental and no controlled studies exist. At best, $\mathrm{LT}_{4}$ therapy has a minor effect on the appearance of new nodules but does not shrink the existing nodules (8). Due to low efficacy and accumulating evidence of cardiovascular and skeletal side-effects, it is not recommended for routine use in recent guidelines $(6,9)$ and reviews $(7,10)$. Iodine supplementation therapy is not superior to $\mathrm{LT}_{4}$ therapy and a major hindrance is the potential induction of hyperthyroidism (11). Conventional (without rhTSH) ${ }^{131}$ I therapy has been used for more than a decade in symptomatic non-toxic MNG, resulting in a mean thyroid volume reduction of $\sim 40 \% 1$ year after treatment (12) and 50-60\% after 3-5 years (13). Generally, patient satisfaction is high and symptoms are considerably improved (14). A major drawback of this therapy is the need for relatively high activities of radioiodine when treating large goitres. Furthermore, the effect is attenuated with increasing goitre size (15). Another challenge is the frequent finding of a low (below $20 \%$ ) thyroid radioiodine uptake (RAIU), caused mainly 
by a high dietary iodine intake and/or by extensive degenerative changes within the thyroid gland.

The recent advent of recombinant human TSH (rhTSH) has opened new avenues for ${ }^{131}$ I therapy of MNG since it can double the thyroid RAIU even using minute quantities (16). In combination with ${ }^{131} \mathrm{I}$ therapy rhTSH enhances the goitre volume reduction (GVR) by $35-56 \%(17-19)$ at the expense of up to fivefold higher rate of permanent hypothyroidism (18). Alternatively, the administered ${ }^{131}$ I-activity can be reduced by a factor corresponding to the rhTSH induced ${ }^{131}$ I-uptake increase, without compromising efficacy (20). The latter strategy of ${ }^{131}$ I therapy with reduced administered ${ }^{131}$ I-activity is intriguing, both in terms of minimizing the long-term risk of extrathyroidal malignancy and in reducing the cost and inconvenience of inpatient treatment. Here, we focus on non-surgical therapeutic aspects of simple MNG, including an update on rhTSH-augmented ${ }^{131}$ I therapy.

\section{Clinical manifestations and natural history of benign non-toxic MNG}

The aetiology, natural history and diagnostic evaluation of MNG has been thoroughly reviewed recently (7). In brief, the natural history of a nodular goitre is that of gradually increasing size with development of multiple nodules. However, the natural history with respect to growth and function varies and is difficult to predict in a given patient because no specific growth parameters exist. The annual growth rate is in the range of $0-20 \%$ and the 5-year incidence of hyperthyroidism is $\sim 10 \%$ (7). Clinical manifestations of nodular goitre are related to those of growth or functional autonomy. Symptoms are typically those of local pressure (dysphagia, globulus sensation, cough or dyspnoea) or cosmetic complaints and are difficult to evaluate objectively. It is mandatory to rule out malignancy, for which purpose fine-needle aspiration biopsy is the golden standard (6). There is no simple relationship between goitre size and symptoms (14), which often makes the decision whether to treat or not difficult. In fact, one-third of clinicians would refrain from treatment facing a patient with moderate discomfort due to a multinodular non-toxic goitre of $50-80 \mathrm{~g}$ in which malignancy has been ruled out $(2,3)$. In asymptomatic subjects with relatively small goitres observation is acceptable, although many have a growth potential.

\section{Non-surgical treatment of benign non-toxic MNG}

\section{Levothyroxine therapy}

$\mathrm{LT}_{4}$ therapy may have a role in the treatment of diffuse goitre, where clinically relevant goitre size reduction (15-40\% after 3 months of therapy) has been documented in controlled trials (21-24). In uninodular goitre, results are conflicting, but there is a trend toward a positive effect in reducing nodule volume after 6-12 months of therapy (25). However, clinically relevant (more than 50\%) nodule or goitre shrinkage occurs only in a minority of patients (10-20\%). Even in the case of a modest effect, a matter of concern is the fact that studies $(26,27)$ have shown re-growth of nodules to baseline levels within 1 year of therapy cessation. Consequently, $\mathrm{LT}_{4}$ therapy has to be continued for many years to benefit the patient. Little is known about long-term outcome and implications on quality of life (QoL). The only available controlled long-term study (28) showed no significant nodule size reduction after 5 years of continuous $\mathrm{LT}_{4}$ therapy. In non-toxic MNG only three controlled trials exist, in which US was used for objective size monitoring $(8,26,29)$. These studies have shown that the effect is at best very modest. Additionally, disqualifying $\mathrm{LT}_{4}$ therapy, there is accumulating evidence of adverse effects on the skeleton and cardiovascular system. In a recent study, we have furthermore demonstrated that the vast majority (91\%) of unselected consecutive Danish MNG patients are ineligible for $\mathrm{LT}_{4}$ therapy, when applying the 2006 guidelines from the Endocrinologists and Associazione Medici Endocrinologi (30). Accordingly, $\mathrm{LT}_{4}$ therapy is not recommended for routine use in recent guidelines and reviews $(6,7,9,10)$.

\section{Iodine supplementation}

Iodine supplementation can effectively reduce a diffuse goitre. In a controlled trial, performed in an iodinedeficient area, a daily dose of $400 \mu \mathrm{g}$ iodine during 8 months was as effective as $150 \mu \mathrm{gT}_{4}$ in reducing the size of endemic goitre (22). The majority of patients in that study had diffuse goitre and iodine supplementation has only been very scarcely evaluated in MNG patients, but it seems no better than $\mathrm{LT}_{4}$ therapy (31). A major hindrance in the use of iodine supplementation is the fact that a sudden increase of the iodine intake may induce thyrotoxicosis in predisposed individuals (11). Furthermore, it is of concern that iodine supplementation appears to increase the incidence of papillary thyroid cancers and lymphocytic thyroiditis (32). Due to these major drawbacks it is disregarded as a therapeutic option in Europe (2) (except in Germany), as well as in North America (3).

\section{Conventional (without rhTSH) radioiodine therapy for non-toxic MNG}

Radioiodine has been used in the treatment of hyperthyroidism for over 60 years. In the last two decades the use has been widened to include symptomatic benign non-toxic goitre, resulting in a mean thyroid volume reduction of $\sim 40 \% \quad 1$ year after 
treatment $(8,12,13,33)$ and $50-60 \%$ after $3-5$ years (13). Approximately half of the effect is obtained within the first 3 months (13). A second ${ }^{131}$ I-dose may cause additional thyroid volume reduction (13). Considerable variation in GVR (15-70\%) is obtained and for incompletely clarified reasons up to $20 \%$ of patients do not respond to ${ }^{131} \mathrm{I}$ therapy (33). The superiority of ${ }^{131} \mathrm{I}$ treatment over $\mathrm{LT}_{4}$ therapy has been demonstrated in a randomized study by Wesche et al. (8). Only a few studies have investigated the effect of ${ }^{131}$ I-treatment in large goitres above $100 \mathrm{ml}$. In three studies in which a sensitive goitre monitoring was applied (i.e. computed tomography (CT) or magnetic resonance (MR) imaging the mean GVR was $30-40 \%$, with considerable individual variation $(15,34,35)$. Interestingly, these studies demonstrated that the GVR is inversely correlated to the initial goitre size (33). Another drawback when treating large goitres is the need for relative high ${ }^{131}$ I activities, thus requiring expensive and inconvenient inpatient treatment. Fractioned ${ }^{131} \mathrm{I}$ therapy is an option in such patients (36), but due to potential thyroid stunning the doses should probably be given with wide intervals, thus rendering this treatment modality cumbersome.

Theoretically, the efficacy of ${ }^{131} \mathrm{I}$ therapy depends mainly on the dose of absorbed radioactivity in the thyroid. When evaluating the outcome of different trials it should be remembered that results are difficult to compare due to variation in both the dose calculation method and in the method for determination of outcome (palpation, US, CT-scan or MRI) in terms of GVR. The issue concerning the optimal dose and dose planning for non-toxic MNG is controversial and much of the literature concerning dose selection deals with hyperthyroid patients (7). Generally, ${ }^{131}$ I-activities have been adjusted to RAIU, aiming at an absorbed thyroid dose of $\sim 100$ Gy $(13,15,33)$, but others question whether this is worthwhile and instead use fixed-dose regimens, only taking thyroid size into consideration (7).

The adverse effects of conventional ${ }^{131}$ I therapy are well documented and described in detail elsewhere (7). Early adverse effects are in most cases mild and transient and include radiation induced thyroiditis (3\%), transient hyperthyroidism (5\%), Grave's-like hyperthyroidism (5\%) and occasionally a 15-25\% increase of thyroid size. A late adverse effect of ${ }^{131} \mathrm{I}$ therapy is the development of hypothyroidism, ranging from 22 to $58 \%$ within $5-8$ years post ${ }^{131}$ I therapy. The long-term risk of extrathyroidal malignancy following ${ }^{131}$ I therapy for non-toxic MNG is unknown. In theory, this risk is higher in euthyroid MNG patients than in hyperthyroid patients, since higher activities of ${ }^{131} \mathrm{I}$ are employed. Thus, a novel strategy using lower activities of ${ }^{131} \mathrm{I}$ is desirable. It is however, reassuring that in a large survey in 35593 hyperthyroid patients, mainly from the USA, followed up for a mean of 21 years, radioiodine therapy was not linked to total cancer deaths or any specific cancer, except for an increase in the standardized mortality ratio for cancer of the thyroid (37). The risk of thyroidal malignancy was assessed in a study of 5000 hyperthyroid patients during 27 years of follow-up (38). In that study, the risk of subsequent thyroid cancer was not significantly increased and bearing in mind that toxic MNG is a different stage of non-toxic MNG, this report is reassuring. But as indicated by the study of Metso et al. the issue is not finally laid to rest (39).

A major hindrance in the use of conventional ${ }^{131} \mathrm{I}$ therapy in MNG is the frequent finding of a low (below $20 \%$ ) thyroid RAIU. In this situation, ${ }^{131}$ I therapy is not feasible since high activities of radioiodine are needed to obtain an acceptable GVR. In such cases, the extrathyroidal irradiation increases and as a consequence the theoretical risk of long-term extrathyroidal malignancy. The thyroid RAIU is dependent on the dietary iodine intake and the extent of nodular autonomy (7). As a consequence of the widespread iodine enrichment programs a low thyroid RAIU is more often encountered.

RhTSH has been documented to increase the thyroid RAIU by more than twofold (20). With regard to the above-mentioned limitations of conventional ${ }^{131} \mathrm{I}$ therapy, rhTSH has the potential to improve GVR when using standard ${ }^{131}$ I activities (18) - or allow treatment with reduced ${ }^{131}$ I activities, without compromising efficacy. In the following we will explore these options.

\section{Radioiodine therapy with rhTSH pre-stimulation \\ Optimal rhTSH dose for enhancement of thyroid RAIU}

Since the initial reports on the effects of rhTSH on thyroid RAIU (40), efforts have focused on determining the optimal dose and timing for rhTSH administration. In the following, we present the current knowledge on the dose and timing of rhTSH (Table 1).

The optimal dose of rhTSH for stimulation of thyroid RAIU remains to be established. Defining a lower dose limit that increases RAIU sufficiently is paramount, since adverse effects, especially the induction of transient thyrotoxicosis, are dose dependent (40-42). The changes in thyroid RAIU following rhTSH doses between 0.01 and $0.9 \mathrm{mg}$ have been investigated in both healthy individuals and patients with MNG (Table 1). In our opinion, data from studies conducted in healthy individuals should not uncritically be applied to MNG patients, since the morphological changes in MNG may indicate an altered and/or delayed physiological response. Generally, studies are difficult to compare due to considerable variations in dietary iodine intake, baseline RAIU and goitre size. The lack of a control group in many studies also complicates the 
Table 1 The effect of recombinant human TSH (rhTSH) on thyroid radioiodine uptake (RAIU) and retained thyroid ${ }^{131}$ I-dose.

\begin{tabular}{|c|c|c|c|c|c|c|}
\hline Author & $n$ & Study design & $\begin{array}{l}\text { Dose rhTSH } \\
(\mathrm{mg})\end{array}$ & $\begin{array}{l}\text { Time interval } \\
\text { between rhTSH } \\
\text { and I-tracer }\end{array}$ & $\begin{array}{l}\text { Baseline } \\
\text { mean RAIU }\end{array}$ & $\begin{array}{l}\text { Relative increase } \\
\text { in mean RAIU }\end{array}$ \\
\hline \multirow[t]{3}{*}{ Huysmans et al. ${ }^{a}$ (2000), (40) } & 15 & Open, non-controlled & 0.01 & $2 \mathrm{~h}$ & $24 \mathrm{~h}: 30 \%$ & $24 \mathrm{~h}: 50 \%$ (median) \\
\hline & & & 0.01 & $24 \mathrm{~h}$ & 24 h: $29 \%$ & 24 h: $90 \%$ (median) \\
\hline & & & 0.03 & $24 \mathrm{~h}$ & 24 h: $33 \%$ & $24 \mathrm{~h}: 100 \%$ (median) \\
\hline \multirow[t]{2}{*}{ Nieuwlaat et al. ${ }^{a}$ (2003), (20) } & 12 & Open, non-controlled & 0.01 & $24 \mathrm{~h}$ & 24 h: $27 \%$ & 24 h: $87 \%$ \\
\hline & 10 & & 0.03 & $24 \mathrm{~h}$ & 24 h: $22 \%$ & $24 \mathrm{~h}: 145 \%$ \\
\hline \multirow[t]{2}{*}{ Duick et al. ${ }^{a}$ (2004), (45) } & 21 & Open, non-controlled & 0.1 & $\mathrm{Oh}$ & - & $48 \mathrm{~h}: 76 \%$ \\
\hline & 9 & & 0.3 & $\mathrm{Oh}$ & - & 48 h: $77 \%$ \\
\hline Silva et al. ${ }^{a}$ (2004), (19) & 17 & Open, non-controlled & 0.45 & $24 \mathrm{~h}$ & $24 \mathrm{~h}: 18 \%$ & $24 \mathrm{~h}: 151 \%$ \\
\hline Albino et al. ${ }^{a}(2005),(43)$ & 18 & Open, non-controlled & $2 \times 0.1$ & $24 \mathrm{~h} / 0 \mathrm{~h}$ & $24 \mathrm{~h}: 12 \%$ & $24 \mathrm{~h}: 335 \%$ \\
\hline Cohen et al. a (2006), (44) & 17 & Open, non-controlled & 0.03 & $24 \mathrm{~h}$ & 24 h: $26 \%$ & 24 h: $68 \%$ \\
\hline Paz-Filho et al. a (2007), (46) & 17 & Open, non-controlled & 0.1 & $24 \mathrm{~h}$ & 24 h: $18 \%$ & $24 \mathrm{~h}: 174 \%$ \\
\hline Torres et al. ${ }^{b}$ (2001), (42) & 6 & Open, non-controlled & 0.9 & $24 \mathrm{~h}$ & 24 h: $23 \%$ & $24 \mathrm{~h}: 75 \%$ \\
\hline \multirow[t]{3}{*}{ Pena et al. ${ }^{\mathrm{b}}$ (2006), (41) } & 5 & Open, non-controlled & 0.1 & $24 \mathrm{~h}$ & 24 h: $25 \%$ & 24 h: $88 \%$ \\
\hline & 10 & & 0.1 & $48 \mathrm{~h}$ & 24 h: $30 \%$ & 24 h: $36 \%$ \\
\hline & 10 & & 0.1 & $72 \mathrm{~h}$ & 24 h: $30 \%$ & $24 \mathrm{~h}: 0 \%$ \\
\hline \multirow[t]{2}{*}{ Lawrence et al. ${ }^{c}$ (2001), (47) } & 4 & Open, non-controlled & 0.9 & $8 \mathrm{~h}$ & $16 \mathrm{~h}: 3.4 \%$ & $16 \mathrm{~h}: 64 \%$ \\
\hline & 5 & & 0.9 & $32 \mathrm{~h}$ & 16 h: $3.2 \%$ & $16 \mathrm{~h}: 100 \%$ \\
\hline \multirow[t]{2}{*}{ Nielsen et al. (2005), (48) } & 35 & $\begin{array}{l}\text { Randomized placebo- } \\
\text { controlled }\end{array}$ & 0.3 placebo & $24 \mathrm{~h}$ before therapy & 24 h: $33 \%$ & 24 h: $43 \%$ \\
\hline & 28 & & & $24 \mathrm{~h}$ before therapy & 24 h: $36 \%$ & $24 \mathrm{~h}:-8 \%$ \\
\hline
\end{tabular}

astudies in patients with multinodular goitre.

${ }^{\mathrm{b}} \mathrm{Studies}$ in healthy individuals.

'Study in iodine loaded healthy men.

interpretation. In addition, measurements of RAIU are extremely prone to variation in the method used. Despite these shortcomings, studies in MNG patients (19, 20, 40, 43-46) and healthy individuals (41, 42, 47) document an approximately twofold increase in RAIU, largely independent of rhTSH dose. In support of this observation, a small comparative trial found that $0.03 \mathrm{mg}$ was not superior to $0.01 \mathrm{mg}(40)$ and another comparative trial observed that $0.3 \mathrm{mg}$ was not superior to $0.1 \mathrm{mg}$ (45). In contrast to these findings, the last comparative trial demonstrated a positive dose response curve, since a relative increase in mean RAIU of $87 \%$ was observed using $0.01 \mathrm{mg}$ of rhTSH compared with $145 \%$ with $0.03 \mathrm{mg}(\mathrm{p}<0.05$, between rhTSH-dose groups) (20). Favouring the use of rhTSH is the concurrent finding that the increase in RAIU is inversely correlated with the initial RAIU (40).

The importance of the stable iodine load was investigated by Lawrence et al. (47), who studied the effect of $0.9 \mathrm{mg}$ of rhTSH in healthy iodine loaded individuals. Although the $16 \mathrm{~h}$ thyroid RAIU doubled (from 3 to $6 \%$ ), it was far from normal by the rhTSH prestimulation, suggesting that reducing iodine intake is paramount.

The retained (effective) ${ }^{131}$ I-dose depends not only on the RAIU but also on the wash-out/release of ${ }^{131} \mathrm{I}$ from the gland. So far, one study has investigated changes in the retained thyroid ${ }^{131}$ I-dose (48), with and without rhTSH. Following $0.3 \mathrm{mg}$ of $\mathrm{rhTSH}$, the retained thyroid ${ }^{131}$ I-dose was increased by $75 \%$ compared with placebo (48) (Fig. 1). Interestingly, the iodine kinetics during conventional (placebo group) ${ }^{131} \mathrm{I}$ therapy resulted in a lower thyroid dose than the intended $100 \mathrm{~Gy}$. The factors responsible for this phenomenon remain unidentified. A plausible explanation is increased iodine release from the gland during therapy and the possible impact from thyroid stunning (49). Apparently, rhTSH reverses this effect. The relative increase in $24 \mathrm{~h}$ RAIU (43\%) was considerably less pronounced in this study (48), which may indicate a methodological problem in the RAIU measurements after ${ }^{131}$ I therapy. In addition, estimation of the effective half-life from two uptake measurements does not reflect the true iodine kinetics and is very prone to inaccuracies in the uptake measurements.

As for minimizing adverse effects, the optimal rhTSH dose is probably $0.1 \mathrm{mg}$ or lower, since doses down to $0.01 \mathrm{mg}$ have proven effective for enhancing RAIU (20, $40,41)$. It is unclear whether large goitres require higher doses of rhTSH for an optimal increase in RAIU.

\section{Timing of rhTSH administration}

Although scarcely investigated the optimal time interval between administration of rhTSH and ${ }^{131} \mathrm{I}$ therapy seems to be $24 \mathrm{~h}$ (Table 1). However, this may be heavily influenced by the characteristics of the study/treatment population. One trial, studying $15 \mathrm{MNG}$ patients, documented that an interval of $24 \mathrm{~h}$ (relative median increase in $24 \mathrm{~h}$ RAIU 90\%) was more effective than $2 \mathrm{~h}$ (relative median increase in $24 \mathrm{~h}$ RAIU 50\%) (40). Considering that the sodium-iodide-symporter is 

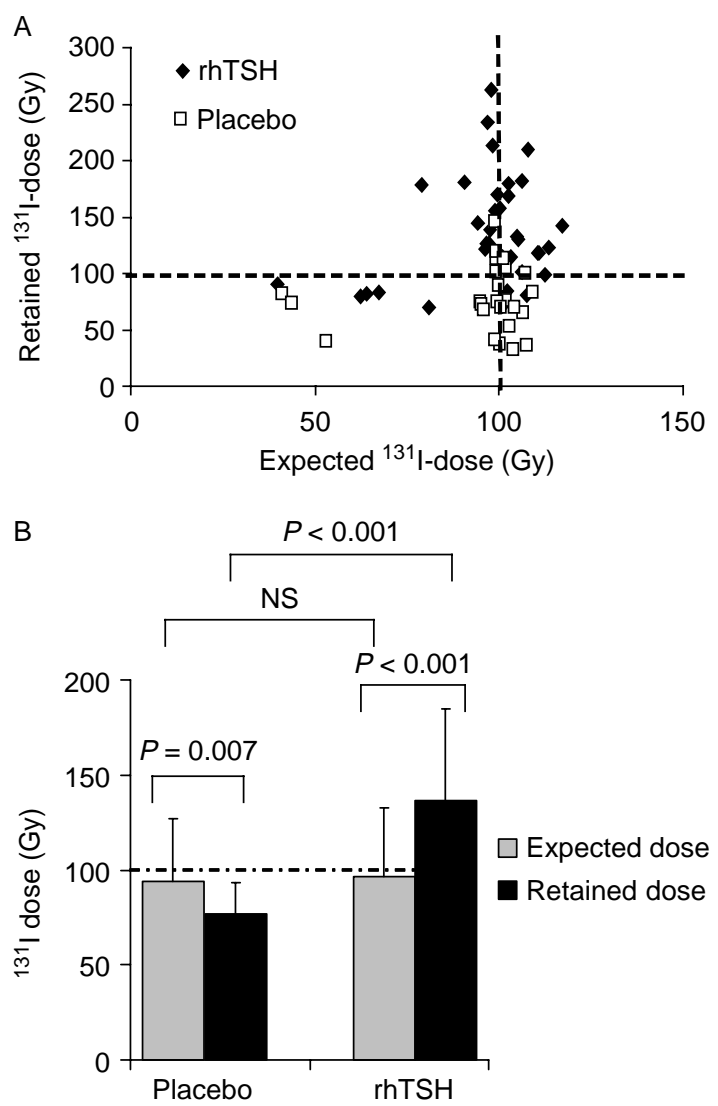

Figure 1 Difference in expected thyroid dose (Gy) and actual absorbed thyroid dose (Gy) after prestimulation with $0.3 \mathrm{mg} \mathrm{rhTSH}$ or placebo. (A) Individual values and (B) comparisons of the mean (S.D.) values for each group. The dotted lines denote the intended dose of 100 Gy, Nielsen et al. 2005 (48).

stimulated by rhTSH with some time delay (50), this is of no surprise. So far, intervals longer than $24 \mathrm{~h}$ have only been studied in healthy individuals, using $0.1 \mathrm{mg}$ of rhTSH (41). This single study points at $24 \mathrm{~h}$ being the optimal interval, since it resulted in a mean increase in the 24 h RAIU from 25 to $47 \%$ (relative increase $88 \%$ ) compared with $30-41 \%$ (relative increase $36 \%$ ) using a $48 \mathrm{~h}$ interval and 30-31\% (no significant increase) using a $72 \mathrm{~h}$ interval (41). These findings need to be confirmed in MNG patients, since the morphologic changes in a MNG may very well result in an altered physiological response (51).

Repetitive injections of rhTSH have been investigated in two trials $(43,52)$. In the first study, $0.1 \mathrm{mg}$ of rhTSH was administered $0 \mathrm{~h}$ and $24 \mathrm{~h}$ respectively, before the ${ }^{131}$ I-tracer, resulting in a fourfold increase in $24 \mathrm{~h}$ RAIU (43). The second injection was probably close to the tracer administration to significantly influence the $24 \mathrm{~h}$ RAIU. The pronounced increase in RAIU in this study (43) may very likely be due to a low baseline RAIU $(12.3 \%)$, more than due to repetitive rhTSH administration. From the aforementioned, we conclude that a $24 \mathrm{~h}$ interval between rhTSH injection and subsequent
131-I therapy seems to be the optimal interval for obtaining an approximate doubling of RAIU in MNG patients, largely independent of the rhTSH dose.

\section{Effect on GVR}

The potential benefits of rhTSH, when combined with ${ }^{131}$ I therapy, are those of increased GVR or reduced administered ${ }^{131}$ I-activity and thus reduced extrathyroidal irradiation. Combined with ${ }^{131}$ I therapy rhTSH increases the GVR in MNG patients by $35-56 \%$. This effect has been documented in three randomized controlled trials (RCT) depicted in Table 2 (17-19). In small-to-medium sized goitres (median goitre volume $51 \mathrm{ml}$, range $20-99 \mathrm{ml}$ ), we demonstrated that $0.3 \mathrm{mg}$ of rhTSH improved the mean GVR by $33 \%$ at 1 year follow-up (Fig. 2) (18). In another study, using $0.3 \mathrm{mg}$ of rhTSH, but in large goitres (median goitre volume $160 \mathrm{ml}$, range $99-440 \mathrm{ml}$ ), the effect of rhTSH was even more pronounced. The average GVR was increased by $56 \%$ compared with conventional ${ }^{131}$ I therapy (Fig. 2) (17). In consistence with these two studies, Silva et al. (19), also treating large goitres (median goitre volume $219 \mathrm{ml}$, range $82-728$ ) but with a fixed ${ }^{131}$ I activity (adjusted to thyroid size), demonstrated a $46 \%$ increase in mean GVR after pre-treatment with $0.45 \mathrm{mg}$ rhTSH and a 12 month follow-up. The remaining non-controlled studies (Table 2) have demonstrated considerable GVR between 35 and 53\% $(20,43,44,46,52,53), 6-12$ months after rhTSHaugmented ${ }^{131}$ I therapy. Although lacking a control group, the results are promising since some of the latter studies $(43,46)$ were carried out in patients with relatively low baseline RAIU, thus demonstrating the feasibility of 131-I therapy in such patients when employing rhTSH. One study, in 18 MNG patients with a baseline RAIU of $12 \%$, documented a mean GVR of $39 \%$ after 6 months and $53 \%$ after 2 years $(43,54)$. Attaining acceptable GVR in patients with a low baseline RAIU is promising, since a high proportion of MNG patients are expected to have low RAIU due to iodization programmes. Before eradicating simple goitre by such programmes, the treatment of patients with existing goitre is in fact impeded.

Another approach is to reduce the administered ${ }^{131} \mathrm{I}$ activity with a factor corresponding to the increase in RAIU obtained by rhTSH stimulation. This strategy was investigated in $22 \mathrm{MNG}$ patients, using 0.01 or $0.03 \mathrm{mg}$ of rhTSH (20). Pre-treatment with rhTSH allowed a $50 \%$ reduction of administered ${ }^{131}$ I activity, while still achieving a GVR of $40 \%$, after 1 year. Such a reduced ${ }^{131}$ I activity is desirable both in terms of lowering the theoretical risk of late occurring extrathyroidal malignancy and in terms of being able to treat patients on an out-patient basis. Minimizing in-patient treatment reduces the economic burden to society and the inconvenience for the patient. 


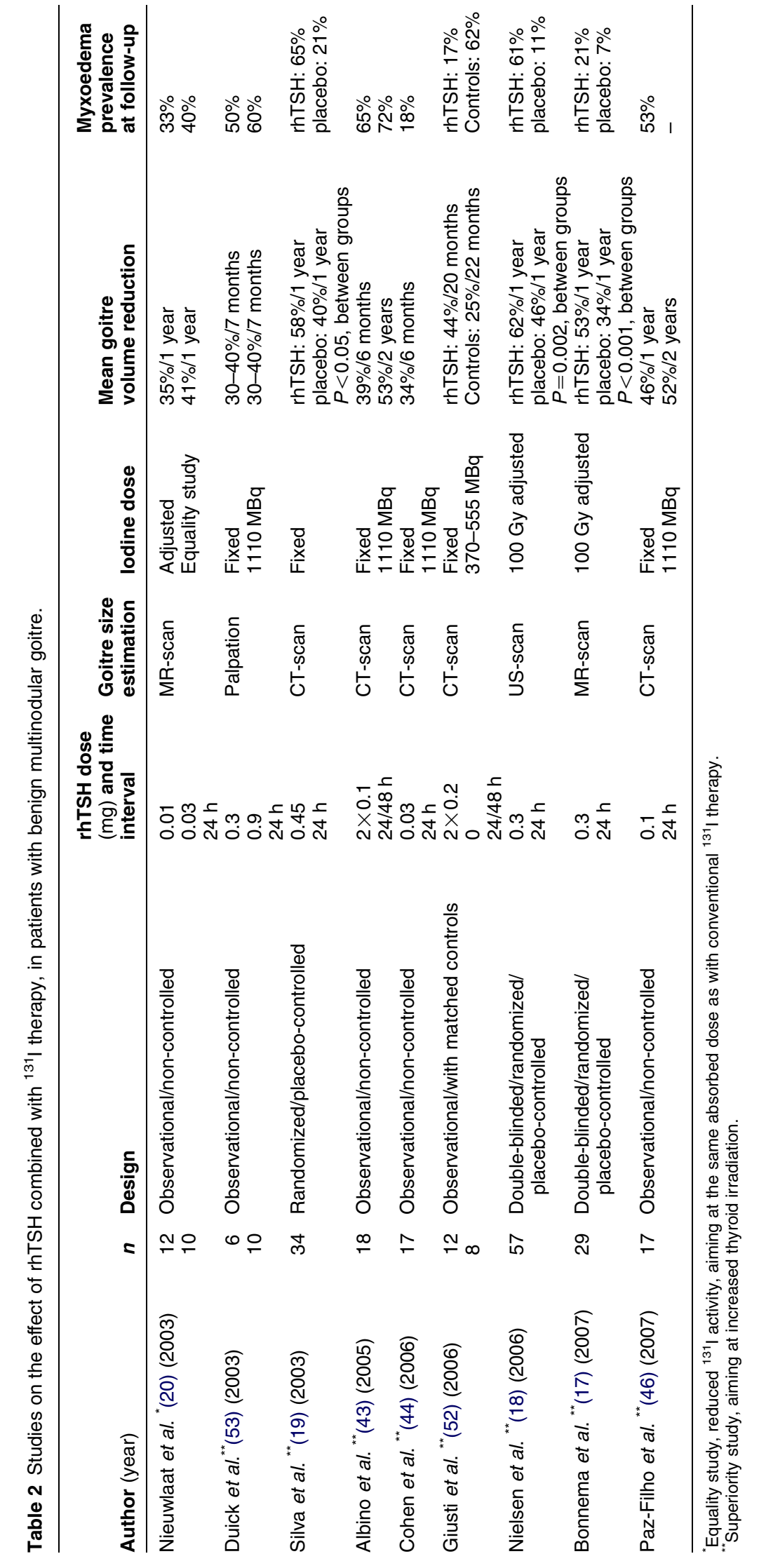




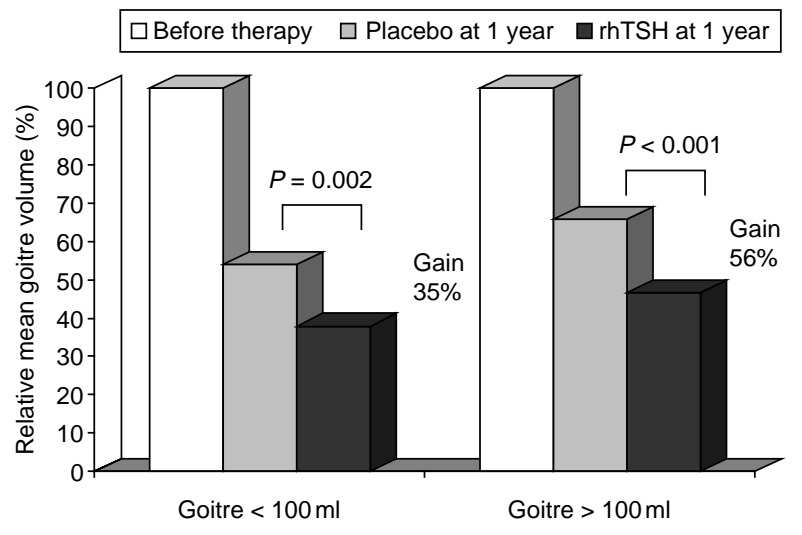

Figure 2 Comparison of the relative goitre volume 1 year after conventional (placebo) and rhTSH augmented ${ }^{131}$ I therapy for non-toxic multinodular goitre, smaller and larger than $100 \mathrm{ml}$. Bars represent the relative mean goitre volume before therapy and 1 year after therapy. Adapted from Nielsen et al. (18) and Bonnema et al. (17).

Three studies have published follow-up results on GVR beyond 1 year $(19,43,46)$. Two small observational studies $(43,46)$ found insignificant GVR between 1 and 2 years of observation (54). In a randomized trial (19), further GVR, in both the rhTSH and the placebo group, was reported, between 1 and 4 years of follow-up. The difference between the groups at 1 year was maintained after 4 years, but was not more pronounced (55).

Although rhTSH amplifies the GVR considerably, the three RCTs have failed to demonstrate an effect on patient satisfaction or QoL (16). One study did not address this issue at all (19), whereas the other two studies $(17,18)$ relied on a visual analogue scale (VAS). Before rhTSH-augmented ${ }^{131}$ I therapy is implemented this issue deserves further attention. It may very well be due to lack of sensitivity of the VAS for QoL determination. Generally, the patient satisfaction is high with conventional ${ }^{131}$ I therapy, which also makes the detection of differences difficult (8). Objective measures to document the superiority of rhTSH augmented ${ }^{131}$ I therapy over conventional ${ }^{131}$ I therapy are thus important. For this purpose, a newly developed thyroid disease specific QoL questionnaire may prove valuable (56).

\section{Impact on tracheal anatomy and respiratory function of ${ }^{131}$ I therapy with and without rhTSH}

Tracheal compression and impaired airflow is often encountered in MNG patients. In a consecutive population of 153 goitre patients it was documented that one-third had upper airway obstruction detected by lung function tests (57). It is important to recognize that affected individuals do not have an increased frequency of respiratory complaints (57), which makes the subjective report of improvement less valuable. Monitoring alterations in pulmonary function and the smallest cross-sectional area of the trachea are obvious methods for documenting a positive effect of ${ }^{131} \mathrm{I}$ therapy. So far only one study (58) in patients with a very large goitre has investigated the effect of rhTSHaugmented ${ }^{131}$ I therapy on these parameters. In that study, we demonstrated that rhTSH-augmented ${ }^{131} \mathrm{I}$ therapy, compared with ${ }^{131}$ I therapy alone, resulted in a greater improvement of the inspiratory function due to a diminished tracheal compression.

\section{Determinants of GVR}

The theoretical foundation of rhTSH augmented ${ }^{131} \mathrm{I}$ therapy is that of increased RAIU leading to increased retained thyroid dose and irradiation. Based on three randomized controlled trials (17-19), pre-treatment with rhTSH beyond doubt improves GVR by 33-56\% compared with conventional ${ }^{131}$ I therapy. But what are the mechanisms behind this enhancement? Employing conventional radioiodine therapy major determinants of GVR are: initial goitre size, retained thyroid dose and as yet unidentified individual susceptibility factors (33). In addition, it has been observed that the presence of dominant nodules (nodule volume $>$ goitre volume) is related to a poorer response to ${ }^{131}$ I therapy and a higher risk of goitre recurrence (33). This indicates that the degree of morphological and/or functional changes, evidenced by US and thyroid scintigraphy, within the thyroid gland may affect the outcome of ${ }^{131}$ I therapy.

\section{Initial goitre size and GVR}

Using conventional non-rhTSH-stimulated ${ }^{131}$ I therapy, several studies have reported a negative correlation between initial goitre size and GVR $(15,33)$, and such a relationship is plausible, because a larger fraction of the gland may become inert and subsequently less susceptible to ${ }^{131}$ I. With the use of rhTSH this negative correlation seems to be abolished. In our recent controlled randomized study, we demonstrated that GVR was inversely correlated to the initial goitre volume in the placebo group, whereas such a correlation did not exist in the rhTSH group (18). A similar pattern was seen in the large goitre study (17) since only rhTSH stimulation had an impact on GVR, when a regression analysis was performed including rhTSH pre-stimulation, age, gender, use of antithyroid drug pretreatment, thyroid $24 \mathrm{~h}^{131} \mathrm{I}$ uptake at baseline, initial goitre volume and serum TSH before therapy.

\section{Degree of morphological/functional changes}

Pre-treatment with rhTSH may improve GVR by causing a more homogeneous distribution of radioiodine within the thyroid, especially increasing the uptake of ${ }^{131} \mathrm{I}$ in 
scintigraphically relatively cold areas. In support of this theory, Nieuwlaat et al. (59) reported a trend toward a more homogeneous distribution of ${ }^{131} \mathrm{I}$, judged by scintigraphy and perhaps even an altered regional uptake, evidenced by cold areas becoming warm and vice versa. This observation has been confirmed by Albino et al. (43). These findings may very well explain the observation that the gain in GVR was more pronounced in large goitres (above $100 \mathrm{ml}$ ), since the degree of both morphological and functional changes within a goitre evolve with increasing goitre size (7).

A highly relevant but unanswered question is whether these rhTSH induced changes in regional RAIU result in a more pronounced nodule reduction, instead of paranodular tissue destruction. The higher prevalence of hypothyroidism with the use of rhTSH suggests that this may not be the case (18).

\section{Retained thyroid dose and GVR}

The retained thyroid dose is positively correlated to GVR using conventional ${ }^{131}$ I therapy $(17,18,33)$. In our double-blinded, randomized and controlled trial we found in the placebo group a significant positive correlation between the degree of goitre reduction and the retained thyroid dose (17). Such a correlation did not exist in the rhTSH group, implying that the goitre reduction was dependent on not only the thyroid dose but also other factors induced by rhTSH pre-stimulation (Fig. 3). In the study by Nielsen et al. (18) a similar pattern was found. By contrast, Albino et al. (43) found a positive correlation between the degree of GVR and the effective absorbed ${ }^{131}$ I-dose preceded by rhTSHstimulation. As mentioned above, a plausible explanation for this additional rhTSH effect beyond the increase in RAIU could merely be a more homogenous distribution of ${ }^{131}$ I within the goitre. However, other, yet unidentified mechanisms behind such an effect, should it exist, could be an increased vulnerability to ionizing radiation of the rhTSH stimulated thyrocytes. In support of this theory, the cure rate, when hyperthyroid patients are treated with ${ }^{131} \mathrm{I}$, is positively correlated to the serum-TSH concentration (60).

Currently, the optimal dose of rhTSH is most likely below $0.1 \mathrm{mg}$, but it should be noted that the serum concentration of rhTSH may be an independent determinant for outcome in terms of GVR. The results of an ongoing phase 2 trial using 0.01 and 0.03 mg of modified release recombinant human TSH (MRrhTSH) as well as studies using different applied ${ }^{131}$ I doses to the thyroid will contribute to resolving these interesting issues.

Whether rhTSH influences the long term GVR or goitre recurrence rate is unclear. Follow-up results have only been scarcely reported, but following conventional ${ }^{131}$ I therapy Le Moli et al. found that $8 \%$ had recurrent goitre growth 3-5 years after therapy (33).

Although it is early to draw final conclusions, it is worth noting that the study by Bonnema et al. (17)

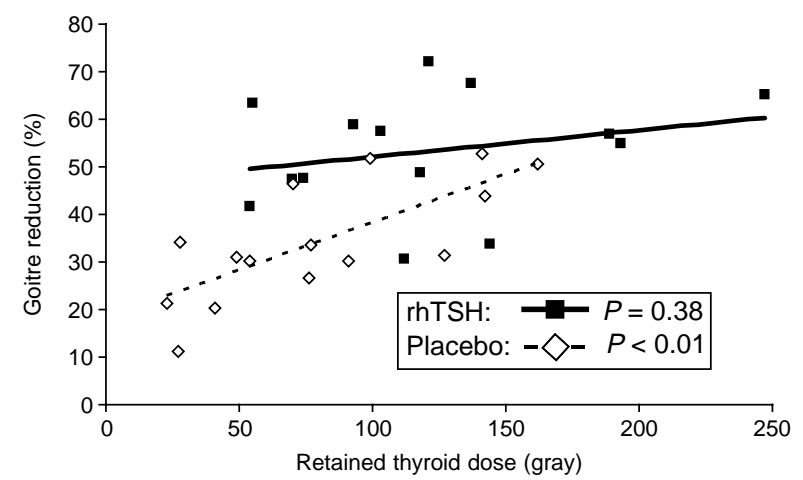

Figure 3 Correlation between the relative goitre volume reduction (GVR) after 12 months and the retained (effective) thyroid ${ }^{131} \mathrm{I}$-dose. Adapted from Bonnema et al. 2007 (17).

documented a $56 \%$ GVR in large goitres, as opposed to the $35 \%$ in small goitres reported by Nielsen et al. (18). If this trend can be confirmed in future studies it indicates that patients with a very large goitre are possibly the best candidates for rhTSH-stimulated ${ }^{131}$ I therapy, especially if the baseline RAIU is low and surgery is disfavoured by the patient or the surgeon.

\section{Adverse effects of recombinant human TSH}

RhTSH has been used in the treatment of differentiated thyroid cancer for more than a decade, and is generally well tolerated, even with repeated doses of $0.9 \mathrm{mg}$ rhTSH. In large-scale clinical studies only a minority of patients had mild adverse reactions, such as nausea and headache (61). In combination with ${ }^{131} \mathrm{I}$ therapy for MNG, acute and long-term alterations in thyroid function and size constitute the main adverse effects in patients with the thyroid gland in situ.

\section{Acute adverse-effects}

The induction of transient dose dependent hyperthyroidism is the main adverse effect of rhTSH. The effects of rhTSH on thyroid function, both in healthy individuals and in patients with MNG, have been studied by us and others $(40-42,62,63)$. Although different doses of rhTSH $(0.01,0.03,0.3$ and $0.9 \mathrm{mg}$ ) have been used, the same patterns in the various biochemical markers have been observed. Within 4-8 h of rhTSH injection, a rise in serum levels of thyroxine $\left(\mathrm{T}_{4}\right)$ and triiodothyronine $\left(\mathrm{T}_{3}\right)$ occurs, peaking at 24-48 h, followed by normalization within 3-4 weeks. A clear dose-response exists, since a more pronounced response in serum levels of $\mathrm{T}_{4}$ and $\mathrm{T}_{3}$ and thyroglobulin was observed when administering $0.3 \mathrm{mg}$ rhTSH, compared with lower doses. A maximal stimulatory dose also seems to exist, since 
$0.9 \mathrm{mg}$ rhTSH did not stimulate thyroid function more than $0.3 \mathrm{mg}$, when administered to the same subjects (42). With rhTSH doses of 0.01 and $0.03 \mathrm{mg}$ the response is blunted and most patients maintain thyroid hormone levels within the normal range (20). Further reassuring is the observation that pre-treatment with $0.1 \mathrm{mg}$ rhTSH did not affect structural and functional parameters of the heart, despite transient increases in serum levels of thyroid hormones (64). Thus, when limiting rhTSH doses to $0.1 \mathrm{mg}$ or less, the rise in thyroid hormones seems to be of little clinical relevance. Nonetheless, caution is advised, especially when treating the elderly or patients with cardiovascular disease.

Acute swelling of the thyroid gland within the first $48 \mathrm{~h}$ following rhTSH injection has been documented in both healthy individuals and MNG patients. Likewise, tumour swelling and pain from metastases, resulting from repeated injections of $0.9 \mathrm{mg}$ rhTSH have been reported in patients with differentiated thyroid carcinoma (65). Thus, $0.9 \mathrm{mg}$ of $\mathrm{rhTSH}$ administered to nine healthy individuals resulted in a 35\% increase in mean thyroid volume at $48 \mathrm{~h}$ (62). One individual developed a very profound and tender thyroid enlargement, from 22 to $90 \mathrm{ml}$. Similarly, when $0.3 \mathrm{mg}$ of rhTSH was administered to $10 \mathrm{MNG}$ patients, a mean volume increase of $24 \%$ was seen after $48 \mathrm{~h}$ (63). In susceptible individuals with a large obstructing goitre this may pose a serious threat in terms of respiratory problems. The concern of airway obstruction following rhTSH augmented ${ }^{131}$ I therapy is enhanced by the observation that conventional ${ }^{131}$ I-treatment itself may result in an acute increase in thyroid volume. Occasionally, thyroid size increase in the range of $15-25 \%$, following conventional ${ }^{131}$ I-treatment, is seen $(15,66)$. If a synergistic effect of rhTSH and ${ }^{131} \mathrm{I}$ on the thyroid swelling exists, combined therapy may pose a serious threat in predisposed individuals. Until now, only one study has evaluated whether rhTSH-augmented ${ }^{131}$ I therapy results in a significant acute goitre swelling (17). In our trial, using $0.3 \mathrm{mg}$ of rhTSH, the average goitre volume remained unchanged 1 week after ${ }^{131} \mathrm{I}$ therapy, but larger deviations from baseline were observed in patients pre-treated with rhTSH compared with placebo (17). The observations in that study are reassuring, but it should be kept in mind that the most pronounced deviations in thyroid size are seen in the first $48 \mathrm{~h}$ after rhTSH administration (62, 63). Although observed in healthy individuals, the acute swelling of MNG tissue is probably dose dependent, since $0.1 \mathrm{mg}$ of rhTSH resulted in a blunted (mean $10 \%$ ) increase in thyroid volume, when administered to 25 healthy individuals (41).

Other adverse reactions, like cervical pain or tenderness, typically occurring in the first three weeks after treatment, are more frequent with the use of rhTSH (17-19). Most likely, these manifestations are a consequence of the increased thyroid irradiation, resulting in an increased incidence of radiation induced thyroiditis.

\section{Long-term adverse effects}

Of more concern than the acute and transient increase in thyroid hormones, is the up to fivefold increase in the rate of permanent hypothyroidism when rhTSH is used in combination with ${ }^{131}$ I therapy (18). In the three randomized controlled trials, permanent hypothyroidism was reported in 21\% (17), 61\% (18) and 65\% (19) of rhTSH treated patients, compared with 7\% (17), 11\% (18) and $21 \%$ (51) respectively, in the controls. Life-long $\mathrm{LT}_{4}$ therapy is needed in these individuals, and since there has been increasing focus on the possibility that hypothyroidism, even if treated with $\mathrm{LT}_{4}$, may result in reduced QoL (67), this issue is clearly of importance. Even so, the higher prevalence of hypothyroidism should not withhold clinicians from using rhTSHaugmented ${ }^{131}$ I therapy in view of the fact that the alternative (surgery) would also lead to hypothyroidism in the majority of cases. Whether the prevalence of hypothyroidism with rhTSH-augmented ${ }^{131} \mathrm{I}$ therapy can be reduced without compromising efficacy (GVR) remains unclear. It is unsettled whether the increased incidence of hypothyroidism is solely caused by the increased absorbed ${ }^{131}$ I-dose, or if the rhTSH dose is an independent factor (48). As seen with conventional ${ }^{131} \mathrm{I}$ therapy, the incidence of hypothyroidism is positively correlated to the GVR. Appearance of TSH receptor antibodies (TRAb) and/or anti-TPO antibodies has been reported in MNG patients following conventional ${ }^{131} \mathrm{I}$ therapy (68). Apparently, the use of rhTSH does not increase this risk (69).

It is unclear whether rhTSH influences the long-term risk of thyroidal or extrathyroidal malignancy and only long-term follow-up studies can clarify this issue. In theory, this would depend on the strategy adopted. If the administered activity is not adjusted for the rhTSH induced increase in RAIU, the absorbed thyroid dose is increased (48) as is perhaps the long-term risk of thyroidal malignancy. On the other hand, one study has demonstrated that if the administered ${ }^{131} \mathrm{I}$ activity is reduced according to the rhTSH induced increase in RAIU, the absorbed radiation-dose can be reduced in extrathyroidal organs and tissues, especially bladder and stomach (70).

\section{Future role and unresolved issues regarding the use of rhTSH in combination with ${ }^{131}$ I therapy}

Pre-treatment with rhTSH beyond doubt improves GVR by $33-56 \%$ compared with conventional ${ }^{131} \mathrm{I}$ therapy. Keeping in mind that rhTSH is used off-label in this setting we suggest that rhTSH may have a future role in ${ }^{131}$ I-treatment of $\mathrm{MNG}$, especially in 
large goitres or in goitres with a low RAIU. Doses of 0.01 and $0.03 \mathrm{mg}$ are effective in increasing the RAIU, but it is too early to offer final recommendations as to the optimal dose of rhTSH. However, there is no evidence to support the use of doses above $0.1 \mathrm{mg}$. The results of an ongoing phase II trial, testing two low doses of modified release rhTSH in combination with ${ }^{131}$ I therapy, will help to clarify this issue.

Surgery remains the first line treatment for large compressive goitres, but rhTSH augmented ${ }^{131}$ I therapy is a promising new strategy in these patients. Another strong argument in favour of rhTSH is the potential to treat with a reduced ${ }^{131}$ I-activity without compromising efficacy. Considering that the issue of risk of extrathyroidal malignancy is not finally laid to rest, this strategy may be worthwhile. In addition, a reduced ${ }^{131}$ I-activity also implies that a higher proportion of patients can be treated on an out-patient basis.

Although rhTSH amplifies the GVR, the failure to demonstrate an effect on patient satisfaction or QoL is problematic (16). This issue deserves further attention to clarify whether it is due to lack of sensitivity of the method for QoL determination. Acute swelling of the thyroid gland has been reported with rhTSH doses above $0.1 \mathrm{mg}$, thus caution should be the rule when treating susceptible individuals with large and/or compressive goitres. This potentially serious side-effect is probably dose dependent, but further studies addressing this and other side-effects, including the long-term effect of the increased hypothyroidism rate, are needed. Most likely, the up to fivefold increase in the rate of permanent hypothyroidism goes hand-in-hand with the improved GVR, but strategies to optimise this imbalance should be explored. In our opinion, the relatively high rate of permanent hypothyroidism does not outweigh the beneficial effect of rhTSH, but points at the importance of identifying the obvious candidates for rhTSH pre-stimulation. Although $\mathrm{LT}_{4}$ substitution therapy is regarded as a routine treatment without side-effects, there has been increasing focus on potential negative implications on QoL.

Future studies will clarify whether the serum rhTSH concentration is an independent factor for GVR. Also, it should be clarified whether rhTSH leads to a better nodule reduction or if the additional effect is mainly related to increased destruction of the 'normal' paranodular tissue. Finally, the risk of goitre recurrence after ${ }^{131}$ I therapy with and without rhTSH should be investigated.

\section{Declaration of interest}

The authors declare that there is no conflict of interest that could be perceived as prejudicing the impartiality of this scientific work.

\section{Funding}

This research did not receive any specific grant from any funding agency in the public, commercial or not-for-profit sector.

\section{Acknowledgements}

We would like to thank the Novo Nordic Foundation, The Agnes and Knut Mørk Foundation, The National Thyroid League, The A P Møller Relief Foundation, The Institute of Clinical Research (University of Southern Denmark), The Hans Skouby and wife Emma Skouby Foundation, Dagmar Marshall's Foundation, Oda Pedersens Research Foundation, King Christian the X's Foundation for supporting our clinical trials in this field over the last decade.

\section{References}

1 Knudsen N, Bulow I, Jorgensen T, Laurberg P, Ovesen L \& Perrild H. Goitre prevalence and thyroid abnormalities at ultrasonography: a comparative epidemiological study in two regions with slightly different iodine status. Clinical Endocrinology 200053 479-485.

2 Bonnema SJ, Bennedbaek FN, Wiersinga WM \& Hegedus L. Management of the nontoxic multinodular goitre: a European questionnaire study. Clinical Endocrinology 200053 5-12.

3 Bonnema SJ, Bennedbaek FN, Ladenson PW \& Hegedus L. Management of the nontoxic multinodular goiter: a North American survey. Journal of Clinical Endocrinology and Metabolism 200287 112-117.

4 Bhagat MC, Dhaliwal SS, Bonnema SJ, Hegedus L \& Walsh JP. Differences between endocrine surgeons and endocrinologists in the management of non-toxic multinodular goitre. British Journal of Surgery 200390 1103-1112.

5 Diehl LA, Garcia V, Bonnema SJ, Hegedus L, Albino CC \& Graf H. Management of the nontoxic multinodular goiter in Latin America: comparison with North America and Europe, an electronic survey. Journal of Clinical Endocrinology and Metabolism $200590117-123$.

6 American Association of Clinical Endocrinologists and Associazione. Medici Endocrinologi medical guidelines for clinical practice for the diagnosis and management of thyroid nodules. Endocrine Practice 200612 63-102.

7 Hegedus L, Bonnema SJ \& Bennedbaek FN. Management of simple nodular goiter: current status and future perspectives. Endocrine Reviews 200324 102-132.

8 Wesche MF, Tiel V, Lips P, Smits NJ \& Wiersinga WM. A randomized trial comparing levothyroxine with radioactive iodine in the treatment of sporadic nontoxic goiter. Journal of Clinical Endocrinology and Metabolism 200186 998-1005.

9 Cooper DS, Doherty GM, Haugen BR, Kloos RT, Lee SL, Mandel SJ, Mazzaferri EL, McIver B, Sherman SI \& Tuttle RM. Management guidelines for patients with thyroid nodules and differentiated thyroid cancer. Thyroid $2006 \mathbf{1 6} 109-142$.

10 Hegedus L. Clinical practice. The thyroid nodule. New England Journal of Medicine 2004351 1764-1771.

11 Roti E \& Uberti ED. Iodine excess and hyperthyroidism. Thyroid 200111 493-500.

12 Hegedus L, Hansen BM, Knudsen N \& Hansen JM. Reduction of size of thyroid with radioactive iodine in multinodular non-toxic goitre. BMJ $1988 \mathbf{2 9 7} 661-662$.

13 Nygaard B, Hegedus L, Gervil M, Hjalgrim H, Soe-Jensen P \& Hansen JM. Radioiodine treatment of multinodular non-toxic goitre. BMJ $1993307828-832$.

14 Bonnema SJ, Nielsen VE \& Hegedus L. Long-term effects of radioiodine on thyroid function, size and patient satisfaction in non-toxic diffuse goitre. European Journal of Endocrinology/European Federation of Endocrine Societies 2004150 439-445.

15 Bonnema SJ, Bertelsen H, Mortensen J, Andersen PB, Knudsen DU, Bastholt L \& Hegedus L. The feasibility of high dose iodine 131 treatment as an alternative to surgery in patients with a very large goiter: effect on thyroid function and size and pulmonary function. Journal of Clinical Endocrinology and Metabolism $1999 \mathbf{8 4}$ 3636-3641. 
16 Nielsen VE, Bonnema SJ \& Hegedus L. The effects of recombinant human thyrotropin, in normal subjects and patients with goitre. Clinical Endocrinology 200461 655-663.

17 Bonnema SJ, Nielsen VE, Boel-Jorgensen H, Grupe P, Andersen PB, Bastholt L \& Hegedus L. Improvement of goiter volume reduction after $0.3 \mathrm{mg}$ recombinant human thyrotropin-stimulated radioiodine therapy in patients with a very large goiter: a doubleblinded, randomized trial. Journal of Clinical Endocrinology and Metabolism 200792 3424-3428.

18 Nielsen VE, Bonnema SJ, Boel-Jorgensen H, Grupe P \& Hegedus L. Stimulation with $0.3-\mathrm{mg}$ recombinant human thyrotropin prior to iodine 131 therapy to improve the size reduction of benign nontoxic nodular goiter: a prospective randomized double-blind trial. Archives of Internal Medicine 2006166 1476-1482.

19 Silva MN, Rubio IG, Romao R, Gebrin EM, Buchpiguel C, Tomimori E, Camargo R, Cardia MS \& Medeiros-Neto G. Administration of a single dose of recombinant human thyrotrophin enhances the efficacy of radioiodine treatment of large compressive multinodular goitres. Clinical Endocrinology $2004 \mathbf{6 0}$ 300-308.

20 Nieuwlaat WA, Huysmans DA, van den Bosch HC, Sweep CG, Ross HA, Corstens FH \& Hermus AR. Pretreatment with a single, low dose of recombinant human thyrotropin allows dose reduction of radioiodine therapy in patients with nodular goiter. Journal of Clinical Endocrinology and Metabolism 200388 3121-3129.

21 Hansen JM, Kampmann J, Madsen SN, Skovsted L, Solgaard S, Grytter C, Grontvedt T \& Rasmussen SN. L-thyroxine treatment of diffuse non-toxic goitre evaluated by ultrasonic determination of thyroid volume. Clinical Endocrinology 197910 1-6.

22 Hintze G \& Kobberling J. Treatment of iodine deficiency goiter with iodine, levothyroxine or a combination of both. Thyroidology 1992 4 37-40.

23 Kreissl M, Tiemann M, Hanscheid H, Rendl J \& Reiners C. Comparison of the effectiveness of two different dosages of levothyroxine-iodide combinations for the therapy of euthyroid diffuse goiter. Deutsche Medizinische Wochenschrift $2001 \mathbf{1 2 6}$ 227-231.

24 Perrild H, Hansen JM, Hegedus L, Rytter L, Holm B, Gundtofte E \& Johansen K. Triiodothyronine and thyroxine treatment of diffuse non-toxic goitre evaluated by ultrasonic scanning. Acta Endocrinologica $1982100382-387$.

25 Sdano MT, Falciglia M, Welge JA \& Steward DL. Efficacy of thyroid hormone suppression for benign thyroid nodules: meta-analysis of randomized trials. Otolaryngology - Head and Neck Surgery 2005 133 391-396.

26 Berghout A, Wiersinga WM, Drexhage HA, Smits NJ \& Touber JL. Comparison of placebo with L-thyroxine alone or with carbimazole for treatment of sporadic non-toxic goitre. Lancet 1990336 193-197.

27 Koc M, Ersoz HO, Akpinar I, Gogas-Yavuz D, Deyneli O \& Akalin S. Effect of low- and high-dose levothyroxine on thyroid nodule volume: a crossover placebo-controlled trial. Clinical Endocrinology 200257 621-628.

28 Papini E, Petrucci L, Guglielmi R, Panunzi C, Rinaldi R, Bacci V, Crescenzi A, Nardi F, Fabbrini R \& Pacella CM. Long-term changes in nodular goiter: a 5-year prospective randomized trial of levothyroxine suppressive therapy for benign cold thyroid nodules. Journal of Clinical Endocrinology and Metabolism $1998 \mathbf{8 3}$ 780-783.

29 Lima N, Knobel M, Cavaliere H, Sztejnsznajd C, Tomimori E \& Medeiros-Neto G. Levothyroxine suppressive therapy is partially effective in treating patients with benign, solid thyroid nodules and multinodular goiters. Thyroid 1997 7 691-697.

30 Fast S, Bonnema SJ \& Hegedus L. The majority of Danish nontoxic goitre patients are ineligible for levothyroxine suppressive therapy. Clinical Endocrinology $200869653-658$.

31 La Rosa GL, Lupo L, Giuffrida D, Gullo D, Vigneri R \& Belfiore A. Levothyroxine and potassium iodide are both effective in treating benign solitary solid cold nodules of the thyroid. Annals of Internal Medicine $19951221-8$.
32 Harach HR \& Williams ED. Thyroid cancer and thyroiditis in the goitrous region of Salta, Argentina, before and after iodine prophylaxis. Clinical Endocrinology 199543 701-706.

33 Le MR, Wesche MF, Tiel-Van Buul MM \& Wiersinga WM. Determinants of longterm outcome of radioiodine therapy of sporadic non-toxic goitre. Clinical Endocrinology $1999 \mathbf{5 0}$ 783-789.

34 de Klerk JM, van Isselt JW, van DA, Hakman ME, Pameijer FA, Koppeschaar HP, Zelissen PM, van Schaik JP \& van Rijk PP. Iodine131 therapy in sporadic nontoxic goiter. Journal of Nuclear Medicine $199738372-376$.

35 Huysmans DA, Hermus AR, Corstens FH, Barentsz JO \& Kloppenborg PW. Large, compressive goiters treated with radioiodine. Annals of Internal Medicine 1994121 757-762.

36 Howarth DM, Epstein MT, Thomas PA, Allen LW, Akerman R \& Lan L. Outpatient management of patients with large multinodular goitres treated with fractionated radioiodine. European Journal of Nuclear Medicine 199724 1465-1469.

37 Ron E, Doody MM, Becker DV, Brill AB, Curtis RE, Goldman MB, Harris BS III, Hoffman DA, McConahey WM, Maxon HR, PrestonMartin S, Warshauer ME, Wong FL \& Boice JD Jr. Cancer mortality following treatment for adult hyperthyroidism. Cooperative Thyrotoxicosis Therapy Follow-up Study Group. Journal of the American Medical Association $1998280347-355$.

38 Angusti T, Codegone A, Pellerito R \& Favero A. Thyroid cancer prevalence after radioiodine treatment of hyperthyroidism. Journal of Nuclear Medicine 200041 1006-1009.

39 Metso S, Jaatinen P, Huhtala H, Auvinen A, Oksala H \& Salmi J. Increased cardiovascular and cancer mortality after radioiodine treatment for hyperthyroidism. Journal of Clinical Endocrinology and Metabolism 200792 2190-2196.

40 Huysmans DA, Nieuwlaat WA, Erdtsieck RJ, Schellekens AP, Bus JW, Bravenboer B \& Hermus AR. Administration of a single low dose of recombinant human thyrotropin significantly enhances thyroid radioiodide uptake in nontoxic nodular goiter. Journal of Clinical Endocrinology and Metabolism $2000 \mathbf{8 5}$ 3592-3596.

41 Pena S, Arum S, Cross M, Magnani B, Pearce EN, Oates ME \& Braverman LE. ${ }^{123}$ I thyroid uptake and thyroid size at 24,48 , and 72 hours after the administration of recombinant human thyroidstimulating hormone to normal volunteers. Journal of Clinical Endocrinology and Metabolism 200691 506-510.

42 Torres MS, Ramirez L, Simkin PH, Braverman LE \& Emerson CH. Effect of various doses of recombinant human thyrotropin on the thyroid radioactive iodine uptake and serum levels of thyroid hormones and thyroglobulin in normal subjects. Journal of Clinical Endocrinology and Metabolism 200186 1660-1664.

43 Albino CC, Mesa CO Jr, Olandoski M, Ueda CE, Woellner LC, Goedert CA, Souza AM \& Graf H. Recombinant human thyrotropin as adjuvant in the treatment of multinodular goiters with radioiodine. Journal of Clinical Endocrinology and Metabolism 2005 $902775-2780$.

44 Cohen O, Ilany J, Hoffman C, Olchovsky D, Dabhi S, Karasik A, Goshen E, Rotenberg G \& Zwas ST. Low-dose recombinant human thyrotropin-aided radioiodine treatment of large, multinodular goiters in elderly patients. European Journal of Endocrinology/European Federation of Endocrine Societies $2006154243-252$.

45 Duick DS \& Baskin HJ. Significance of radioiodine uptake at 72 hours versus 24 hours after pretreatment with recombinant human thyrotropin for enhancement of radioiodine therapy in patients with symptomatic nontoxic or toxic multinodular goiter. Endocrine Practice 200410 253-260.

46 Paz-Filho GJ, Mesa-Junior CO, Olandoski M, Woellner LC, Goedert CA, Boguszewski CL, Carvalho GA \& Graf H. Effect of $30 \mathrm{mCi}$ radioiodine on multinodular goiter previously treated with recombinant human thyroid-stimulating hormone. Brazilian Journal of Medical and Biological Research $2007 \mathbf{4 0} 1661-1670$.

47 Lawrence JE, Emerson CH, Sullaway SL \& Braverman LE. The effect of recombinant human tsh on the thyroid (123)I uptake in iodide treated normal subjects. Journal of Clinical Endocrinology and Metabolism $2001 \mathbf{8 6} 437-440$. 
48 Nielsen VE, Bonnema SJ, Boel-Jorgensen H, Veje A \& Hegedus L. Recombinant human thyrotropin markedly changes the ${ }^{131} \mathrm{I}$ kinetics during ${ }^{131}$ I therapy of patients with nodular goiter: an evaluation by a randomized double-blinded trial. Journal of Clinical Endocrinology and Metabolism 200590 79-83.

49 Postgard P, Himmelman J, Lindencrona U, Bhogal N, Wiberg D, Berg G, Jansson S, Nystrom E, Forssell-Aronsson E \& Nilsson M. Stunning of iodide transport by (131)I irradiation in cultured thyroid epithelial cells. Journal of Nuclear Medicine 200243 828-834.

50 Kogai T, Endo T, Saito T, Miyazaki A, Kawaguchi A \& Onaya T. Regulation by thyroid-stimulating hormone of sodium/iodide symporter gene expression and protein levels in FRTL-5 cells. Endocrinology $19971382227-2232$.

51 Fast S, Grupe P, Nielsen VE, Bonnema SJ \& Hegedus L. Influence of the interval $(24,48$, or 72 hours) between the administration of $0.1 \mathrm{mg}$ recombinant human thyrotropin (rhTSH) and subsequent thyroid radioiodine uptake in nontoxic goiter patients. Evaluation by a randomized double-blinded trial. ETA annual meeting. Abstract No. 045, 2008.

52 Giusti M, Cappi C, Santaniello B, Ceresola E, Augeri C, Lagasio C \& Minuto F. Safety and efficacy of administering $0.2 \mathrm{mg}$ of recombinant human TSH for two consecutive days as an adjuvant to therapy with low radioiodine doses in elderly out-patients with large nontoxic multinodular goiter. Minerva Endocrinologica 2006 31 191-209.

53 Duick DS \& Baskin HJ. Utility of recombinant human thyrotropin for augmentation of radioiodine uptake and treatment of nontoxic and toxic multinodular goiters. Endocrine Practice 2003 9 204-209.

54 Paz-Filho GJ, Mesa CO, Carvalho GA, Goedert CA \& Graf H. Recombinant human TSH associated with radioiodine does not have further effects on thyroid volume and function after 2 years. Clinical Endocrinology $200869345-346$.

55 Cardia MS, Rubio IG \& Medeiros-Neto G. Prolonged follow-up of multinodular goitre patients treated with radioiodine preceded or not by human recombinant TSH. Clinical Endocrinology $2006 \mathbf{6 4}$ 474.

56 Watt T, Rasmussen AK, Groenvold M, Bjorner JB, Watt SH, Bonnema SJ, Hegedus L \& Feldt-Rasmussen U. Improving a newly developed patient-reported outcome for thyroid patients, using cognitive interviewing. Quality of Life Research 200817 1009-1017.

57 Gittoes NJ, Miller MR, Daykin J, Sheppard MC \& Franklyn JA. Upper airways obstruction in 153 consecutive patients presenting with thyroid enlargement. BMJ 1996312484.

58 Bonnema SJ, Nielsen VE, Boel-Jorgensen H, Grupe P, Andersen PB, Bastholt L \& Hegedus L. Recombinant human thyrotropinstimulated radioiodine therapy of large nodular goiters facilitates tracheal decompression and improves inspiration. Journal of Clinical Endocrinology and Metabolism 200893 3981-3984.

59 Nieuwlaat WA, Hermus AR, Sivro-Prndelj F, Corstens FH \& Huysmans DA. Pretreatment with recombinant human TSH changes the regional distribution of radioiodine on thyroid scintigrams of nodular goiters. Journal of Clinical Endocrinology and Metabolism 200186 5330-5336.

60 Bonnema SJ, Bennedbaek FN, Veje A, Marving J \& Hegedus L. Propylthiouracil before 131I therapy of hyperthyroid diseases: effect on cure rate evaluated by a randomized clinical trial. Journal of Clinical Endocrinology and Metabolism $2004 \mathbf{8 9}$ 4439-4444.

61 Ladenson PW, Braverman LE, Mazzaferri EL, Brucker-Davis F, Cooper DS, Garber JR, Wondisford FE, Davies TF, DeGroot LJ, Daniels GH, Ross DS \& Weintraub BD. Comparison of administration of recombinant human thyrotropin with withdrawal of thyroid hormone for radioactive iodine scanning in patients with thyroid carcinoma. New England Journal of Medicine 1997337 888-896.

62 Nielsen VE, Bonnema SJ \& Hegedus L. Effects of $0.9 \mathrm{mg}$ recombinant human thyrotropin on thyroid size and function in normal subjects: a randomized, double-blind, cross-over trial. Journal of Clinical Endocrinology and Metabolism 200489 2242-2247.

63 Nielsen VE, Bonnema SJ \& Hegedus L. Transient goiter enlargement after administration of $0.3 \mathrm{mg}$ of recombinant human thyrotropin in patients with benign nontoxic nodular goiter: a randomized, double-blind, crossover trial. Journal of Clinical Endocrinology and Metabolism 200691 1317-1322.

64 Barca MF, Gruppi C, Oliveira MT, Romao R, Cardia MS, Rubio I, Knobel M \& Medeiros-Neto G. Cardiovascular assessment of hyperthyroid patients with multinodular goiter before and after radioiodine treatment preceded by stimulation with recombinant human TSH. Endocrine 200732 175-181.

65 Giovanni V, Arianna LG, Antonio C, Francesco F, Michele K, Giovanni S, Marco S \& Giovanni L. The use of recombinant human TSH in the follow-up of differentiated thyroid cancer: experience from a large patient cohort in a single centre. Clinical Endocrinology $200256247-252$.

66 Nygaard B, Faber J \& Hegedus L. Acute changes in thyroid volume and function following ${ }^{131}$ I therapy of multinodular goitre. Clinical Endocrinology $1994 \mathbf{4 1} 715-718$.

67 Grozinsky-Glasberg S, Fraser A, Nahshoni E, Weizman A \& Leibovici L. Thyroxine-triiodothyronine combination therapy versus thyroxine monotherapy for clinical hypothyroidism: meta-analysis of randomized controlled trials. Journal of Clinical Endocrinology and Metabolism $2006912592-2599$.

68 Nygaard B, Knudsen JH, Hegedus L, Scient AV \& Hansen JE. Thyrotropin receptor antibodies and Graves' disease, a side-effect of ${ }^{131}$ I treatment in patients with nontoxic goiter. Journal of Clinical Endocrinology and Metabolism 199782 2926-2930.

69 Rubio IG, Perone BH, Silva MN, Knobel M \& Medeiros-Neto G. Human recombinant $\mathrm{TSH}$ preceding a therapeutic dose of radioiodine for multinodular goiters has no significant effect in the surge of TSH-receptor and TPO antibodies. Thyroid 200515 134-139.

70 Nieuwlaat WA, Hermus AR, Ross HA, Buijs WC, Edelbroek MA, Bus JW, Corstens FH \& Huysmans DA. Dosimetry of radioiodine therapy in patients with nodular goiter after pretreatment with a single, low dose of recombinant human thyroid-stimulating hormone. Journal of Nuclear Medicine 200445 626-633.

Received 1 December 2008

Accepted 23 December 2008 